\title{
Ensinando e aprendendo Física Moderna e Contemporânea através da integração das mídias
}

\author{
Daniela Fontana Almenara ${ }^{1}$ - danialmenara@gmail.com, Carlos Mergulhão Júnior², Frederico Trindade \\ Teófilo $^{3}$, Elexlhane Guimarães Damasceno de Siqueira ${ }^{4}$ \\ 1, 2, 3, 4 Universidade Federal de Rondônia (UNIR)
}

Palavras-Chave: Física Moderna, Tecnologias Educacionais, Gamificação.

\section{Introdução}

A Física em muitas escolas brasileiras é ensinada de forma descontextualizada, dando ênfase à memorização e aplicação direta de fórmulas, a própria carga horária impossibilita o aprofundamento e a introdução de certos conceitos. Muitos estudantes têm contato com conceitos de Física Moderna e Contemporânea (FMC) devido ao acesso aos meios de comunicação, o que torna esses conhecimentos parte do senso comum dos mesmos, cabendo à escola aperfeiçoar este conhecimento.

A proposta de abordar conteúdos de FMC no ensino médio já tem sido discutida na literatura. Wolf e Mors (2006) propõem uma abordagem histórica e conceitual para o ensino de relatividade no ensino médio, Ostermann (1999) faz uma abordagem sobre temas de física contemporânea no ensino médio utilizando pôster.

Face o exposto propomos como produto educacional a aplicação de três sequências didáticas, que envolverão tópicos de FMC e serão desenvolvidas utilizando ferramentas gratuitas e disponíveis na web, tais como Midiacode que é um editor e leitor de QR Codes, o criador de linhas do tempo Laifi e o construtor de projetos gráficos Canva, que facilitam a produção e publicação de material autoral.

\section{Metododologia e material}

A proposta de ensino e aprendizagem consiste na aplicação de sequências didáticas com uso de tecnologias digitais em uma abordagem ausubeliana, considerando aspectos históricos da Ciência, e suas relações com a tecnologia e a sociedade, favorecendo a aprendizagem significativa de conceitos e a melhoria na compreensão quanto à natureza da Ciência.

A primeira sequência é uma atividade gamificada com uso de elementos de design de game, para motivar, aumentar a atividade, e reter a atenção do usuário (DETERDING et al., 2011). A atividade utiliza QR codes e explora o surgimento da Teoria da Relatividade e da Mecânica Quântica. O objetivo desse jogo é constituir-se em um "organizador prévio" e desenvolver conceitos subsunçores proporcionando a aprendizagem por consequência (MOREIRA, 2006).

$\mathrm{Na}$ segunda sequência didática os estudantes conhecerão a ferramenta Laifi, um construtor de linhas do tempo, que podem ser compartilhadas e editadas em conjunto. Produzirão pesquisas, selecionarão informações, imagens e vídeos, a fim de apresentar a trajetória dos cientistas Max Plank, Marie Curie, Nikola Tesla, Niels Bohr, Albert Einstein e Stephen Hawking e suas contribuições à Ciência.

Na última sequência, os estudantes pesquisarão sobre os princípios físicos associados ao funcionamento de equipamentos construídos a partir de descobertas da FMC, tais como: TV de LCD e plasma, painéis solares, diodo, transístor, laser e equipamento de raios-x. Construirão infográficos com a ferramenta Canva apresentando as informações com elementos gráfico-visuais (fotografia, desenho, diagrama estatístico etc.) integrados em textos sintéticos e dados numéricos.

Nesse contexto o papel da pesquisadora será o de propor e estimular atividades conjuntas e relações colaborativas entre os estudantes, mediando o processo de aprendizagem por meio da utilização de tecnologias.

\section{Resultados esperados e discussão}

A aplicação desse produto educacional constituído por sequências didáticas busca promover aproximação dos estudantes com a disciplina de Física por meio da introdução de tópicos de FMC

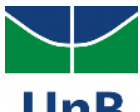


utilizando como suporte pedagógico tecnologias digitais. O sucesso desse projeto poderá melhorar os índices de aprovação na disciplina de Física nas turmas em que será desenvolvido, mudar os conceitos dos estudantes sobre ciências, promover o encontro entre teoria e prática, e ainda influenciá-los na escolha de profissões que promovam a área de Física.

Espera-se que os estudantes aprendam a fazer pesquisas, produzir textos autorais, trabalhar em grupos, utilizar diversas ferramentas tecnológicas, o que contribuirá no desenvolvimento de habilidades. O resultado obtido resultará em um material que será disponibilizado a outros professores e alunos, os quais poderão incorporar ao seu processo de ensino e aprendizagem ou ainda contribuir para a melhoria do mesmo.

\section{Considerações Finais}

Diariamente surgem novas tecnologias capazes de atrair a atenção dos estudantes e tornase mais difícil promover a sua participação nas atividades de sala de aula. Os Parâmetros Curriculares Nacionais para o Ensino Médio apontam para uma reformulação do currículo de Física e sinalizam a inserção da FMC nos currículos como forma de atrair jovens para a carreira científica, disseminando os conhecimentos que a ciência e a tecnologia propiciam à população. Gil et al. (1987, apud OSTERMANN, 2004, p.25) acreditam que o ensino de Física Moderna e Contemporânea a alunos de Ensino Médio tem grande importância, já que a introdução de tópicos atuais de Física podem contribuir para dar uma imagem mais precisa da ciência e do próprio trabalho científico.

Nesse contexto, o desenvolvimento de uma prática pedagógica, voltada para a integração das mídias ao currículo escolar e a utilização da gamificação como estratégia de engajamento, se revelam aliadas capazes de promover interação e tornar as aulas produtivas, aproximando os estudantes à disciplina e promovendo uma aprendizagem significativa dos conceitos físicos.

Hoje o que se exige do indivíduo não é um grande acúmulo de informações, e sim o desenvolvimento de competências, habilidades e atitudes que favoreçam a produção de conhecimento atualizado, autonomia e habilidade cognitiva, para compreender e atuar na sociedade informacional, que para se desenvolverem dependem do planejamento e mediação do professor.

\section{Agradecimentos}

À Capes pela bolsa de estudos, ao Governo do Estado de Rondônia, a Equipe Gestora e aos alunos da E.E.E.F.M. Cel. Aluízio Pinheiro Ferreira pelo apoio e participação no projeto. Ao meu orientador Dr. Carlos Mergulhão Júnior pela paciência e orientações.

\section{Referências}

DETERDING, S. et al.From game design elements to gamefulness: defining "gamification". In: INTERNATIONAL ACADEMIC MINDTREK CONFERENCE: ENVISIONING FUTURE MEDIA ENVIRONMENTS, 15., 2011, Tampere. Proceedings... New York:Acm, 2011. p.9-15. MOREIRA, M. A. A teoria da aprendizagem significativa e sua implementação em sala de aula. Brasília: Editora Universidade de Brasília, 2006.

OSTERMANN, F., Física Moderna e Contemporânea no Ensino Médio: elaboração de material didático em forma de pôster sobre partículas elementares e interações fundamentais, Cad. Cat. Ens. Fís., v. 16, n. 3: p. 267-286, 1999.

OSTERMANN, F; RICCI, T. S. F. Construindo uma unidade didática conceitual sobre Mecânica Quântica: um estudo na formação de professores de Física. Ciência \& Educação, Bauru, v. 11, n. 2, p. 235-258, maio 2004.

WOLFF, J.F.S., e MORS, P.M., Relatividade no ensino médio: uma experiência com motivação na história, Experiências em Ensino de Ciências, 2006. 